\title{
The failure of Ricardian equivalence under dynastic altruism*
}

\author{
Philippe MICHEL ${ }^{\dagger}$ \\ IUF-EUREQua and University Paris I \\ and \\ Emmanuel THIBAULT $\S$ \\ GREMAQ - Toulouse School of Economics (TSE)
}

\begin{abstract}
This paper investigates the theoretical accuracy of the Barro (1974) debt neutrality proposition. We first identify a discrepancy between the transversality condition of a social planning problem and the one of altruistically-linked overlapping generations. Then, this discrepancy is exploited to construct public debt policies which affect the competitive equilibrium allocation even when bequests are strictly positive in all periods: a violation of Ricardian equivalence.
\end{abstract}

Keywords: Public debt, Ricardian equivalence, intergenerational altruism.

JEL Classification: H 6, E 13, C 6 .

${ }^{*}$ We thank Sabrina Buti, Fabrice Collard, Helmuth Cremer, Bruno Decreuse, Per Krusell, Franck Portier, Gilles Saint Paul, Jean Tirole, Alain Venditti and Bertrand Wigniolle. We also thank participants to international conferences where this paper was presented: the Society for Economic Dynamics (SED) 2003 Annual Meeting (University Paris I Sorbonne), the Public Economic Theory (PET) 2005 Annual Meeting (University Aix-Marseille II) and the European Economic Association (EEA) 2005 Annual Congress (University of Amsterdam). The usual disclaimer applies. After this paper was completed but before it was published Philippe Michel passed away. We will miss him.

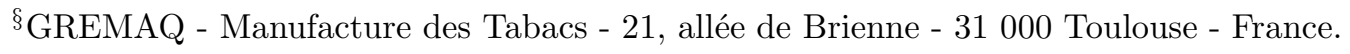

Tel: (+33)-5-61-12-85-74 Fax: (+33)-5-61-22-55-63 E-mail: emmanuel.thibault@univ-tlse1.fr 


\section{Introduction}

Ricardian Equivalence suggests that government attempts to influence demand using fiscal policy will prove fruitless. As the idea of Ricardian equivalence contrasts with alternative Keynesian theories, it has been extraordinarily important within the academic debate over government debt (See Seater (1993) and Elmendorf and Mankiw (1999) for an analysis of this theoretical and empirical debate).

In 1974 Barro revived Ricardo's idea of the offsetting of public by private transfers, leading to the neutrality of public debt. Barro's analysis of debt neutrality is based on the assumption that individuals are motivated by a special form of intergenerational altruism (dynastic altruism), whereby individuals have an altruistic concern for their children, who in turn also have altruistic feelings for their own children, and so on. Through such a recursive relation all generations of a single family (a dynasty) are linked together by a chain of private intergenerational transfers, countervailing any attempt by the government to redistribute resources across generations. This offsetting of public by private transfers operates only if bequests are positive. This is a crucial qualification to Barro's debt neutrality result. ${ }^{1}$

The aim of this paper is to show that, contrary to widespread belief, the strictly positivity of bequest is only a necessary (but not a sufficient) condition to obtain the Barro's debt neutrality result. Indeed, we construct in this paper public debt policies which affect the competitive equilibrium allocation even when bequests are strictly positive in all periods: a violation of Ricardian equivalence.

To construct non-neutral public debt policies in the Barro (1974)'s setting, we exploit a discrepancy between the transversality condition of a social planner problem and the one of altruistically-linked overlapping generations. In the former, the discounted value of wealth tends to zero whereas in the latter the discounted value of bequests tends to zero. As the bequest of an altruistic agent, who lives a finite number of periods, only includes the wealth transmitted to the next generation (and not all the assets of the economy), the transversality condition of a social planner

\footnotetext{
${ }^{1}$ This important issue has been studied by several economists. Following Philippe Weil's 1987 seminal article, there now exist some explicit conditions under which bequests are positive (see, e.g., Abel (1987) or, recently, Thibault (2004, 2005)).
} 
implies the one of an altruist; but the converse is not necessarily true.

According to this difference, the intertemporal budget constraint of the government is not the mirror of the intertemporal budget constraint of a private agent and we can exhibit non-neutral public debt policies such that both the government debt is honored at each date and the government deficit is sustainable in the long-run. Then, the necessary and sufficient condition to retrieve the Barro's debt neutrality proposition is that both the bequests are strictly positive and the intertemporal budget constraint of the government holds. However, this latter condition is not an intertemporal equilibrium condition and is still debated in OLG economies (see, e.g., Wilcox (1989) or, recently, de la Croix and Michel (2002) for main outlines on this issue).

The paper is organized as follows. Section 2 is devoted to the characterization of the intertemporal equilibrium of the dynastic altruism model and the comparison with the planner's optimal solution. In Section 3, we establish the existence of nonneutral public debt policies in the Barro (1974)'s setting. The algorithm to construct non-neutral public debt policy is collected in Appendix A.

\section{The dynastic altruism framework}

In this section, we examine the intertemporal equilibrium of the dynastic altruism model, assuming that production occurs according to a neoclassical production function. After characterizing this competitive intertemporal equilibrium, we compare it with the optimal growth path chosen by a social planner.

\section{Intertemporal equilibrium of the dynastic altruism economy.}

In this subsection, the Barro (1974)-Weil (1987) framework is introduced and intertemporal equilibria of this model are defined. We consider a perfectly competitive economy which extends over infinite discrete time. Production occurs according to a constant returns to scale technology $F\left(K_{t}, L_{t}\right)$ using two inputs, capital, $K_{t}$, and labor, $L_{t}$. The production function is homogenous of degree one, allowing us to write output per unit of labor as a function of capital per unit of labor: $f(k)=F(k, 1)$ where $k=K / L$ is the capital stock per unit of labor. For all positive $k$ we assume 
that $f(k)>0, f^{\prime}(k)>0$ and $f^{\prime \prime}(k)<0$. Capital fully depreciates after one period. Since markets are perfectly competitive, each factor is paid its marginal product (the wage $w_{t}$ and the interest factor $R_{t}$ ):

$$
w_{t}=f\left(k_{t}\right)-k_{t} f^{\prime}\left(k_{t}\right) \quad \text { and } \quad R_{t}=f^{\prime}\left(k_{t}\right)
$$

Individuals are identical within as well as across generations and live for two periods. In each period $t, N_{t}$ individuals are born, where $N_{t}$ grows at rate $n$. Young altruists born at time $t$ supply one unit of labor, receive the market wage $w_{t}$, inherit $x_{t}$, consume $c_{t}$ and save $s_{t}$. They consume $d_{t+1}$, part of the proceeds of their savings, and leave a non-negative bequest $x_{t+1}$ to each of their $1+n$ children when they are old.

Agents are price-takers and face the following budget constraints:

$$
\begin{gathered}
x_{t}+w_{t}=c_{t}+s_{t} \\
R_{t+1} s_{t}=d_{t+1}+(1+n) x_{t+1} \quad \text { with } \quad x_{t+1} \geq 0
\end{gathered}
$$

The life-cycle utility $U\left(c_{t}, d_{t+1}\right)$ of an agent depends on his consumptions $c_{t}$ and $d_{t+1}$. The definition of altruism adopted by Barro (1974) is the following: parents care about their children's welfare by weighting their children's utility in their own utility function $V_{t}$. Then, the total utility of an agent born in $t$ is:

$$
\begin{gathered}
V_{t}\left(x_{t}\right)=\max _{c_{t}, s_{t}, d_{t+1}, x_{t+1}}\left\{U\left(c_{t}, d_{t+1}\right)+\gamma V_{t+1}\left(x_{t+1}\right)\right\} \\
\text { s.t. (2) and (3). }
\end{gathered}
$$

where $V_{t+1}\left(x_{t+1}\right)$ denotes the utility of a representative descendant who inherits $x_{t+1}$. Parameter $\gamma \in(0,1)$ is the intergenerational discount factor or degree of altruism. ${ }^{2}$

To characterize the solution of this Bellman Equation, ${ }^{3}$ we consider the Lagrangean $\mathcal{L}_{t}$ of period $t$ :

$$
\mathcal{L}_{t}=U\left(c_{t}, d_{t+1}\right)+\frac{\gamma}{1+n} p_{t+1}\left[R_{t+1}\left(x_{t}+w_{t}-c_{t}\right)-d_{t+1}\right]-p_{t} x_{t}
$$

\footnotetext{
${ }^{2}$ We retrieve the standard Diamond (1965) model when $\gamma=0$.

${ }^{3}$ For a thorough presentation of this discrete time optimization, see Mc Kenzie (1986).
} 
which is equal to the sum of the life-cycle utility $U\left(c_{t}, d_{t+1}\right)$ and the increase in the shadow value (in terms of utility) of $x_{t}$ over one period, ${ }^{4} \gamma p_{t+1} x_{t+1}-p_{t} x_{t}$.

For all $t \geq 0$, maximizing the Lagrangean with respect to $c_{t}$ and $d_{t+1}$ gives:

$$
U_{c}^{\prime}\left(c_{t}, d_{t+1}\right)=\frac{\gamma}{1+n} p_{t+1} R_{t+1} \quad \text { and } \quad U_{d}^{\prime}\left(c_{t}, d_{t+1}\right)=\frac{\gamma}{1+n} p_{t+1}
$$

For all $t \geq 1$, maximizing $\mathcal{L}_{t}$ with respect to $x_{t}$ subject to $x_{t} \geq 0$ gives:

$$
-p_{t}+\frac{\gamma}{1+n} p_{t+1} R_{t+1} \leq 0 \quad\left(=0 \text { if } x_{t}>0\right)
$$

And the transversality condition is: ${ }^{5} \lim _{t \rightarrow+\infty} \gamma^{t} p_{t} x_{t}=0$

Given the purpose of our paper, we can simplify its mathematical treatment by adopting a log-linear life-cycle utility: $U\left(c_{t}, d_{t+1}\right)=\ln c_{t}+\beta \ln d_{t+1}$ with $\beta>0$.

Then, merging the previous equations, the (necessary and sufficient) first-order conditions for an interior optimum with operative bequest motive (i.e., $x_{t+1}>0$ ) can be rewritten as follows:

$$
\begin{gathered}
\frac{c_{t+1}}{c_{t}}=\frac{\gamma R_{t+1}}{1+n} \\
\frac{\beta}{d_{t+1}}=\frac{\gamma}{(1+n) c_{t+1}} \\
\lim _{t \rightarrow+\infty} \gamma^{t} \frac{x_{t}}{c_{t}}=0
\end{gathered}
$$

Thus, the conditions $(2)$ to $(5)$ and $\left(\mathcal{T}_{x}\right)$ characterize the behavior of an altruist when bequests are strictly positive.

The equilibrium conditions on the labor market and the good market are respectively $L_{t}=N_{t}$ and $F\left(K_{t}, L_{t}\right)=N_{t} c_{t}+N_{t-1} d_{t}+K_{t+1}$.

\footnotetext{
${ }^{4}$ The current shadow price $p_{t+1}$ of bequest $x_{t+1}$ in period $t+1$ is discounted by the factor $\gamma$ in order to define the increase in shadow value (calculated) in period $t$.

${ }^{5}$ The transversality condition is sufficient for optimality. It is necessary if a feasible path with zero bequest provides a finite value to the objective function (see Michel $(1982,1990)$ ).
} 
The capital stock of period $t+1$ is financed by the savings of the generation born in $t: K_{t+1}=N_{t} s_{t}$. Hence, in intensive form, we have on the good market:

$$
(1+n) k_{t+1}=f\left(k_{t}\right)-c_{t}-\frac{d_{t}}{1+n}
$$

The initial conditions $k_{0}=K_{0} / N_{0}, x_{0} \geq 0$ and $d_{0}>0$ are given and verify: ${ }^{6}$

$$
d_{0}+(1+n) x_{0}=R_{0}(1+n) k_{0}=f^{\prime}\left(k_{0}\right)(1+n) k_{0}
$$

By definition, conditions $(2)$ to $(7)$ and $\left(\mathcal{T}_{x}\right)$ characterize an intertemporal equilibrium $\left\{\hat{c}_{t}, \hat{d}_{t+1}, \hat{x}_{t+1}, \hat{k}_{t+1}\right\}_{t \geq 0}$ of the dynastic altruism economy. In the rest of this paper we assume the uniqueness of this intertemporal equilibrium.

\section{Comparison with the planner's optimal solution.}

Importantly, since bequests $\hat{x}_{t+1}$ are strictly positive at all dates $t$, it is wellknown (see, e.g., Blanchard and Fischer (1989)) that the sequence $\left\{\hat{c}_{t}, \hat{d}_{t+1}, \hat{k}_{t+1}\right\}_{t \geq 0}$ coincides with the optimal growth path $\left\{c_{t}^{\star}, d_{t+1}^{\star}, k_{t+1}^{\star}\right\}_{t \geq 0} \operatorname{chosen}^{7}$ by a social planner. Indeed, the objective $\mathcal{W}$ of the social planner is to maximize the sum of the life-cycle utility of all current and future generations, discounted at rate $\gamma$ and subject to the resource constraints of the economy. Then, the social planner maximizes:

$$
\begin{gathered}
\mathcal{W}=\max _{c_{t}, k_{t}, d_{t+1}} \sum_{t=0}^{+\infty} \gamma^{t} U\left(c_{t}, d_{t+1}\right)=\max _{c_{t}, k_{t}, d_{t+1}} \sum_{t=0}^{+\infty} \gamma^{t}\left[\ln c_{t}+\beta \ln d_{t+1}\right] \\
\text { s.t. (6). }
\end{gathered}
$$

The solution of the social planning problem necessarily satisfies both the resource constraint (6) and the trade-off conditions (4) with $R_{t+1}=f^{\prime}\left(k_{t+1}\right)$ and (5). Finally, the transversality condition for the social planner is:

$$
\lim _{t \rightarrow+\infty} \gamma^{t} \frac{k_{t+1}}{c_{t}}=0
$$

These conditions are sufficient to determine the optimal path associated with the optimal growth problem (namely, the optimal growth path). Then, according to (1) and (4) to (6), the dynamics of the optimal growth path are defined by:

\footnotetext{
${ }^{6}$ In order to simplify our study, we assume that $d_{0}$ is given; a thorough analysis of the first old agents is available in Michel, Thibault and Vidal (2006).

${ }^{7}$ Since $\gamma<1$, we know that this optimal solution exists.
} 


$$
\begin{aligned}
& c_{t+1}=\frac{\gamma f^{\prime}\left(k_{t+1}\right)}{1+n} c_{t}=\frac{\gamma}{(1+n) \beta} d_{t+1} \\
& (1+n) k_{t+1}=f\left(k_{t}\right)-c_{t}-\frac{d_{t}}{1+n}
\end{aligned}
$$

After substitution of $d_{t}$, these arbitrage and resource $(\mathcal{A R})$ conditions $^{8}$ define a dynamic system $\left(c_{t}, k_{t}\right)$ of dimension two. Initial values of $k_{0}$ (and $\left.d_{0}\right)$ are given but not $c_{0}$. Then, it is the transversality condition $\left(\mathcal{T}_{k}\right)$ which allows to determine the optimal initial consumption $c_{0}^{\star}$. However, note that there are many other solutions to equations $(\mathcal{A R})$. In fact, for any $0<c_{0}<c_{0}^{\star}$, there exists a unique solution of $(\mathcal{A R}){ }^{9}$

We represent in Figure 1 this solution in two cases.
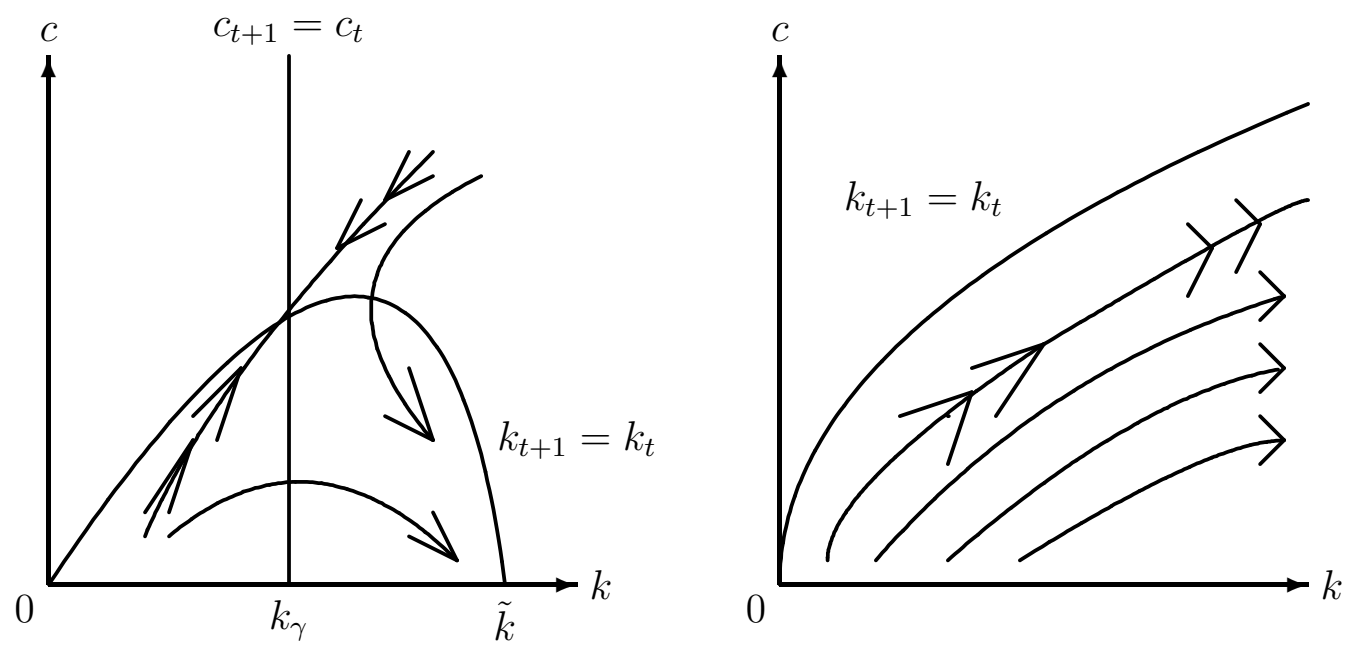

Figure 1: The optimal growth path

When the production function satisfies Inada conditions, the modified golden rule capital stock $k_{\gamma}$ exists $\left(f^{\prime}\left(k_{\gamma}\right)=(1+n) / \gamma\right)$. The optimal path (represented with double arrows in our figure) converges to $k_{\gamma}$ and all the others paths satisfying the $(\mathcal{A R})$ conditions converge to $\tilde{k}$ (the positive solution of $f(k)=(1+n) k)$.

We have also represented the case in which the lowest marginal productivity $\lim _{k \rightarrow+\infty} f^{\prime}(k)$ is positive and larger than $\gamma /(1+n)$. In such a case, for all feasible paths

\footnotetext{
${ }^{8}$ When (1) is satisfied, the conditions (4) to (6) are equivalent to $(\mathcal{A R})$.

${ }^{9}$ Note that, for $c_{0}>c_{0}^{\star}$, solutions of equation $(1+n) k_{t+1}=f\left(k_{t}\right)-c_{t}-d_{t} /(1+n)$ cease to be defined because $k_{t}$ would become negative.
} 
starting from $c_{0}<c_{0}^{\star}$, we have $c_{t+1} / c_{t}>1$ and $c_{t}$ and $k_{t}$ tend to $+\infty$.

We conclude this section by remarking that condition $\left(\mathcal{T}_{k}\right)$ is equivalent to the intertemporal budget constraint of a government in the decentralized economy. But this condition is not a consequence of the private intertemporal equilibrium condition which is equivalent to $\left(\mathcal{T}_{x}\right)$. We come back to this important issue in the next section.

\section{The debt non-neutrality result}

In this section we first exhibit an algorithm to construct public debt policies which affect the competitive equilibrium allocation even when bequests are strictly positive in all periods: a violation of Ricardian equivalence. Then, we discuss both the robustness and the relevancy of these non-neutral public debt policies.

\section{Existence of non-neutral public debt policies.}

To illustrate the non-neutrality of public debt in Barro's (1974) model, we assume that, at each period $t$, government issues a public debt $B_{t}$. This debt must repay the debt of the preceding period $B_{t-1}$ plus the accrued interest. It is financed by a lump-sum tax $\tau_{t}$ on the income of the young households. The government always honors its debt. We thus have: $B_{t}=R_{t} B_{t-1}-N_{t} \tau_{t}$; or in intensive form, with $b_{t}=B_{t-1} / N_{t}$ the debt stock per young household at the beginning of period $t$ :

$$
(1+n) b_{t+1}=R_{t} b_{t}-\tau_{t}=f^{\prime}\left(k_{t}\right) b_{t}-\tau_{t}
$$

Without loss of generality, we assume that the initial debt $b_{0}$ is nil.

Note that in the definition of the intertemporal equilibrium with public debt, there are only two changes. Indeed, the budget constraint of the young is now:

$$
x_{t}+w_{t}-\tau_{t}=c_{t}+s_{t}
$$

and savings finance both the capital stock and the public debt: $N_{t} s_{t}=K_{t+1}+B_{t}$, or equivalently:

$$
s_{t}=(1+n)\left(k_{t+1}+b_{t+1}\right)
$$

According to Barro (1974), this government debt policy redistributes the tax burden among generations. But families, smoothing their consumption over time, 
reverse the effects of this redistribution through their bequests. Thus, government debt seems to be completely neutral because the overlapping generations of altruists linked by strictly positive bequests can be interpreted as a social planner.

This intuition is reinforced by the fact that, according to the previous section, the equivalence between an intertemporal equilibrium $\left\{\hat{c}_{t}, \hat{d}_{t+1}, \hat{k}_{t+1}\right\}_{t \geq 0}$ of the dynastic altruism economy and the optimal growth path $\left\{c_{t}^{\star}, d_{t+1}^{\star}, k_{t+1}^{\star}\right\}_{t \geq 0}$ is valid when there is no public debt.

However, we show in the next proposition that this equivalence is not always valid when the government issues debt. Consequently, there exist non-neutral public debt policies in Barro's (1974) model.

\section{Proposition 1 The DeBT NON-NEUTRALITY REsulT}

Public debt is non-neutral. More precisely, any sequences of consumptions, capital stock and positive bequests that satisfy the arbitrage and resource conditions $(\mathcal{A R})$ and the transversality condition $\left(\mathcal{T}_{x}\right)$ define an intertemporal equilibrium with debt.

As shown in Appendix $A$, for any sequence $\left\{\bar{c}_{t}, \bar{d}_{t+1}, \bar{k}_{t+1}\right\}_{t \geq 0}$ of consumptions and capital stock which satisfies $(\mathcal{A R})$, and for any sequence of positive numbers $\left\{\bar{x}_{t+1}\right\}_{t \geq 0}$ which satisfies:

$$
\lim _{t \rightarrow+\infty} \gamma^{t} \frac{\bar{x}_{t}}{\bar{c}_{t}}=0
$$

there exists a sequence of values $\left\{\bar{b}_{t+1}\right\}_{t \geq 0}$ defined by:

$$
(1+n) \bar{b}_{t+1}=\frac{\bar{d}_{t+1}+(1+n) \bar{x}_{t+1}}{f^{\prime}\left(\bar{k}_{t+1}\right)}-(1+n) \bar{k}_{t+1}
$$

such that $\left\{\bar{c}_{t}, \bar{d}_{t+1}, \bar{x}_{t+1}, \bar{k}_{t+1}, \bar{b}_{t+1}\right\}_{t \geq 0}$ corresponds to an intertemporal equilibrium with debt $\bar{b}_{t+1}$ and bequest $\bar{x}_{t+1}$. This implies that any path of consumptions and capital stock satisfying $(\mathcal{A R})$ corresponds to an intertemporal equilibrium with debt and positive bequest. Indeed it is sufficient to choose $\bar{x}_{t}=\bar{c}_{t}, t \geq 1$. $^{10}$

We now discuss the intuition underlying our non-neutrality result. For each sequence of consumptions, capital stock and positive bequests that satisfies $(\mathcal{A R})$ and $\left(\mathcal{I}_{x}\right)$ (but not $\left(\mathcal{T}_{k}\right)$ ), a public debt path is shown to be non-neutral in the framework

\footnotetext{
${ }^{10}$ Note that $x_{0}\left(=\bar{x}_{0}\right)$ is unchanged and satisfies $(7)$.
} 
of Barro (1974). Even if these sequences of consumptions, capital stock and positive bequests may tend to some extreme values, they allow us to show that an infinite number of non-neutral public debt paths exists in Barro (1974).

Then, this non-neutrality property of government debt can be due to the difference between the transversality condition of a social planning problem and the one of altruistically-linked overlapping generations. Intuitively, there always exist public debt policies (i.e., intergenerational redistributions) such that their introduction implies that the wealth discounted value does not tend to zero while the bequests discounted value tend to zero. As already shown, the intertemporal budget constraint of the government $\left(\mathcal{T}_{k}\right)$ is not the mirror of the intertemporal budget constraint of a private agent (here, equation $\left(\mathcal{T}_{x}\right)$ ).

Notice that the literature on the sustainability of government deficit has increasingly focused on the role of the intertemporal budget constraint of the government. In this literature, sustainability should be understood in the sense of solvency (see, e.g., Wilcox (1989) or Buiter and Kletzer (1998)).

In OLG models, de la Croix and Michel (2002, chapter 4) show that the conclusion on whether the intertemporal budget constraint of the government should hold depends crucially on the number of available fiscal instruments. When there are two types of taxes (three instruments) there is no restriction on government borrowing. On the contrary, when there is only one type of tax (two instruments) the debt level that can decentralized a given trajectory is determined. However, this unique debt trajectory may or may not satisfy the intertemporal budget constraint of the government, depending on the accumulation regime (under or over accumulation).

Our result exhibits some similarities with that obtained by Crettez, Michel and Wigniolle (2002) in the Ramsey (1928)'s framework. They show that for a given path of government expenditures, there generally exists a continuum of equilibria (characterized by different paths of consumption and leisure) depending on various debt policies. The infinitely lived representative consumer model used by Crettez, Michel and Wigniolle (2002) appears as a more drastic framework than our Barro's framework to obtain the non-neutrality result. Indeed, in Barro's model, the transversality condition depends on the bequests, and not on the total amount 
of wealth held by agents. ${ }^{11}$ This difference explains both why non-ricardian trajectories can be constructed more easily in the Barro's model and why non-neutral public debt policies in which government is debtor ${ }^{12}$ cannot be excluded.

\section{References}

Abel, A.B., 1987, Operative gift and bequest motives, American Economic Review, 77, 1037-1047.

Barro, R.J., 1974, Are government bonds net wealth?, Journal of Political Economy, 82, 1095-1117.

Blanchard, O.J. and S. Fischer, 1989, Lecture on macroeconomics, The M.I.T. Presss, Cambridge.

Buiter, W.H. and K.M. Kletzer, 1998, Debt and taxes: Ponzi finance, dynamic efficiency and government solvency, in Market behaviour and macroeconomic modelling, Brakman, Van Ees and Kuipers eds, London: Mc Millan Press.

Crettez, B., Michel Ph. and B. Wigniolle, 2002, Debt neutrality and the infinitelived representative consumer, Journal of Public Economic Theory, 4, 499-521.

de la Croix, D. and Ph. Michel, 2002, A theory of growth: dynamics and policy in overlapping generations, Cambridge University Press.

Diamond, P.A., 1965, National debt in a neoclassical growth model, American Economic Review, 55, 1126-1150.

Elmendorf, D.W. and N.G. Mankiw, 1999, Government debt, Handbook of Macroeconomics, (J. Taylor and M. Woodford eds), Elsevier-North Holland, Chapter 25 (Vol 1C), 1615-1669.

Mc Kenzie, L.W., 1986, Optimal economic growth, turnpike theorems and comparative dynamics, Handbook of Mathematical Economics, vol 3, (K.J. Arrow and M.D. Intriligator eds), Elsevier-North Holland, Chapter 26 (Vol 3), 1281-1355.

\footnotetext{
${ }^{11}$ Whereas the transversality condition $\left(\mathcal{T}_{k}\right)$ of an infinitely lived agent implies the transversality condition of an altruist $\left(\mathcal{T}_{x}\right)$, the converse is not true. Indeed, according to (1), (3) and since $s_{t}=$ $(1+n) k_{t+1}$, we have $0 \leq(1+n) x_{t+1}=f^{\prime}\left(k_{t+1}\right)(1+n) k_{t+1}-d_{t+1}$. Then: $0 \leq x_{t+1} \leq f^{\prime}\left(k_{t+1}\right) k_{t+1}$. Therefore, according to (4): $0 \leq x_{t+1} \leq \frac{(1+n)}{\gamma} \frac{c_{t+1}}{c_{t}} k_{t+1}$. Hence we have: $0 \leq \gamma^{t+1} x_{t+1} / c_{t+1} \leq$ $\gamma^{t} k_{t+1} / c_{t}$. According to these equations, $\left(\mathcal{T}_{k}\right)$ implies $\left(\mathcal{T}_{x}\right)$.

${ }^{12}$ According to Appendix A, the sequence $\left\{\bar{b}_{t+1}\right\}_{t \geq 0}$ defined by (11) is a sequence of positive value as soon as we choose $\bar{x}_{t}>\bar{k}_{t} f^{\prime}\left(\bar{k}_{t}\right)$.
} 
Michel, Ph., 1982, On the transversality condition in infinite horizon optimal problems, Econometrica, 50, 975-85.

Michel, Ph., 1990, Some clarifications on the transversality condition, Econometrica, 58, 705-723.

Michel, Ph., Thibault, E. and J.P. Vidal, 2006, Intergenerational altruism and neoclassical growth models, Handbook of the Economics of Giving, Reciprocity and Altruism, (S.C. Kolm and J. Mercier Ythier eds), Elsevier-North Holland, Chapter 15 (Vol 2), 1055-1106.

Ramsey, F.P., 1928, A mathematical theory of saving, Economic Journal, 38, 543-559.

Seater, J., 1993, Ricardian equivalence, Journal of Economic Literature, 31, 142-190.

Thibault, E., 2004, The power of love, Economics Letters, 84, 183-189.

Thibault, E., 2005, Existence and specific characters of rentiers: a savers-spenders theory approach, Economic Theory, 25, 401-419.

Weil, P., 1987, Love thy children. Reflections on the Barro debt neutrality theorem, Journal of Monetary Economics, 19, 377-391.

Wilcox, D., 1989, The sustainability of government deficits: implications of the present value borrowing constraint, Journal of Money, Credit and Banking, 21, 291306.

\section{Appendix A: Proof of Proposition 1}

We use three steps to show our debt non-neutrality result:

(i) Step 1: Characterization of intertemporal equilibria with public debt.

We begin to show that a sequence of values of $\left\{\bar{c}_{t}, \bar{d}_{t+1}, \bar{x}_{t+1}, \bar{k}_{t+1}, \bar{b}_{t+1}\right\}_{t \geq 0}$ corresponds to an intertemporal equilibrium with debt of the dynastic altruism economy if and only if it verifies for all $t \geq 0$ the arbitrage and resource constraints $(\mathcal{A R})$, the transversality condition $\left(\mathcal{T}_{x}\right)$ and the equation:

$$
\bar{x}_{t+1}=f^{\prime}\left(\bar{k}_{t+1}\right)\left(\bar{k}_{t+1}+\bar{b}_{t+1}\right)-\frac{\bar{d}_{t+1}}{1+n}
$$

Indeed, (12) is the second budget constraint (3) when $s_{t}$ is given by (10). The others conditions $(\mathcal{A R})$ and $\left(\mathcal{T}_{x}\right)$ are not modified. All these conditions are neces- 
sary. To show that they are sufficient, we define prices by (1), savings by (10) and taxes by (8). Then, it remains only to prove that (9) is verified (all other equilibrium conditions result from $(\mathcal{A R}),\left(\mathcal{T}_{x}\right)$ and $\left.(12)\right)$. Using $(\mathcal{A R})$ and (8) we have: $\bar{c}_{t}+\tau_{t}=f\left(\bar{k}_{t}\right)-(1+n) \bar{k}_{t+1}-\bar{d}_{t} /(1+n)+f^{\prime}\left(\bar{k}_{t}\right) \bar{b}_{t}-(1+n) \bar{b}_{t+1}$. Using (12) (or (7) for $t=0)$ we obtain: $\bar{c}_{t}+\tau_{t}=f\left(\bar{k}_{t}\right)-s_{t}+\bar{x}_{t}-f^{\prime}\left(\bar{k}_{t}\right) \bar{k}_{t}=w_{t}-s_{t}+\bar{x}_{t}$.

\section{(ii) Step 2: Construction of an intertemporal equilibrium with public debt.}

Consider a sequence of positive values $\left\{\bar{c}_{t}, \bar{d}_{t+1}, \bar{k}_{t+1}\right\}_{t \geq 0}$ which satisfies $(\mathcal{A R})$ and a sequence of non-negative numbers $\left\{\bar{x}_{t+1}\right\}_{t \geq 0}$ which satisfies $\left(\mathcal{T}_{x}\right)$. The conditions $(\mathcal{A R}),\left(\mathcal{T}_{x}\right)$ and $(12)$ are verified with debt defined by (11) and $x_{t+1}=\bar{x}_{t+1}$. Then, according to Step $1,\left\{\bar{c}_{t}, \bar{d}_{t+1}, \bar{x}_{t+1}, \bar{k}_{t+1}, \bar{b}_{t+1}\right\}_{t \geq 0}$ is an intertemporal equilibrium with public debt.

\section{$\underline{\text { (iii) Step 3: Existence of non-neutral public debt policies. }}$}

Let $\left\{\bar{c}_{t}, \bar{d}_{t+1}, \bar{k}_{t+1}\right\}_{t \geq 0}$ be a sequence of positive values which satisfies $(\mathcal{A R})$ and $\left(\mathcal{T}_{x}\right)$ but does not satisfies $\left(\mathcal{T}_{k}\right)$. According to Section 2 (and Figure 1), such a sequence exists but it is not an optimal growth path. From $\bar{c}_{t}$ we can define $\bar{x}_{t}$ as follows: $\bar{x}_{t}=\bar{c}_{t}$. Then, since $\gamma<1$, we have constructed a sequence of positive numbers $\left\{\bar{x}_{t+1}\right\}_{t \geq 0}$ which satisfies $\left(\mathcal{T}_{x}\right)$. Hence, according to Step 2, when $\bar{b}_{t+1}$ is defined by (12), $\left\{\bar{c}_{t}, \bar{d}_{t+1}, \bar{x}_{t+1}, \bar{k}_{t+1}, \bar{b}_{t+1}\right\}_{t \geq 0}$ corresponds to an intertemporal equilibrium with debt $\bar{b}_{t+1}$ and strictly positive bequest $\bar{x}_{t+1}$.

Since each non-optimal trajectory which satisfies $(\mathcal{A R})$ can be an intertemporal equilibrium with debt, the public debt policy $\left\{\bar{b}_{t+1}\right\}_{t \geq 0}$ is non-neutral. Qed. 